\title{
Socialização e Modos de Ser Jovem em Área Rural na Bahia
}

\author{
Socialization and Youth Behavior in the Rural Areas of Bahia
}

\author{
Catarina Malheiros da Silva \\ Universidade de Brasília \\ catems14@yahoo.com.br
}

\section{Resumo}

O estudo 'Escola, saberes e cotidiano no meio rural: um estudo sobre os/as jovens do Sertão da Bahia' se propôs a compreender e analisar os sentidos da escola e dos papéis de gênero, desempenhados por rapazes e moças que vivem no sertão da Bahia. Realizou-se um trabalho de campo, no qual a observação participante, a etnografia e a realização de grupos de discussão constituíram os principais instrumentos de coleta de dados. Foram realizados 10 grupos de discussão com jovens do sexo masculino e feminino, estudantes de uma escola em um Distrito rural, em Município Baiano. Os resultados da pesquisa desenvolvida identificam uma tensão entre os/as jovens, pois as moças mostram-se resistentes ao modelo de comportamento instituído para ambos, denunciando a existência de uma socialização de rapazes e moças distinta e eficiente, aportada num padrão de conduta rígido e moralista para com o sexo feminino.

Palavras-chave: Juventude rural; gênero; socialização

\begin{abstract}
The research 'Escola, saberes e cotidiano no meio rural: um estudo sobre os/as jovens do Sertão da Bahia' (School, knowledge and day-to-day life in rural areas: a study about the youth in the backlands of Bahia) aimed to understand and analyze the senses of school and the gender roles played by boys and girls living in the backlands of Bahia. A field work was done in which participative observation, ethnography and discussion groups were the main instruments for gathering data. Ten discussion groups were assembled with male and female youngsters, students at a rural district school in a municipality in Bahia. The research results identified a tension among the youngsters, since girls are resistant to the models of behavior that were instituted for both genders, which shows the existence of a distinct and efficient socializing conduct for girls and boys, settled in a rigid and moralistic behavior pattern towards the female gender.
\end{abstract}

Keywords: Rural youth; gender; socialization 


\section{Reflexões Iniciais}

Considerando a centralidade dos espaços educativos e do grupo de amigos para a socialização de muitos jovens rurais brasileiros, este artigo se propõe a compreender e analisar os sentidos atribuídos à condição de ser jovem e os papéis de gênero desempenhados por moças e rapazes que vivem em área rural na Bahia.

O entendimento sobre a juventude rural supõe o reconhecimento da existência de espaços distintos - a exemplo da casa, da vizinhança e da cidade - onde os/as jovens vivenciam cotidianamente experiências individuais e coletivas. Sobre a importância da comunidade local para os jovens rurais, Brandão (1995, p.136) afirma que: "quando há vizinhos por perto, parentes ou não, os grupos de idade alargam os limites da ordem familiar cotidiana e se constituem como os primeiros espaços extra familiares de convivência e socialização". Nesses espaços, os jovens constroem relações com amigos, vivenciam o lazer, estabelecem relações com os meios de comunicação de massa, participam de manifestações culturais e religiosas, expressando um sentimento de pertencimento, tanto à comunidade como a grupos de jovens. Nesse sentido, as experiências cotidianas dos jovens dependem da intensidade e da riqueza da vida social existente no meio rural (WANDERLEY, 2006).

O cotidiano visto sob o signo da regularidade, normatividade e repetitividade manifesta-se como um campo de ritualidades, sendo a rotina "um elemento básico das actividades sociais do dia a dia" (PAIS, 2003b, p.28). A vida cotidiana é uma esfera da realidade constituída por fatos anônimos e transitórios, suscetível a mudanças e modificações. Ainda, para Pais: "torna-se necessário que os jovens sejam estudados a partir de seus 'contextos vivenciais, quotidianos,' porque é quotidianamente, [...] isto é, no curso das suas interações, que os jovens constroem formas sociais de consciência, de pensamento, de percepção e acção" (PAIS, 2003a, p.70). Daí a relevância da valorização do lugar social da juventude rural, com suas especificidades. Para Vieira (2006), contrariamente à ideia ainda vigente de que só restam no campo os mais velhos em algumas regiões do país o meio rural concentra uma parcela significativa de jovens homens e mulheres que constroem distintas trajetórias e formas de pensar e de vivenciar suas condições juvenis.

\section{Itinerário da Pesquisa}

A pesquisa que subsidia as discussões apresentadas no presente artigo foi realizada para elaboração de uma dissertação de mestrado na UnB, com jovens estudantes do Distrito rural Espraiado, no município de Palmas de Monte Alto (BA). Buscou compreender e analisar o significado das experiências escolares para a formação de jovens que vivem no Sertão da Bahia, além de investigar suas vivências cotidianas e projetos de futuro. O critério de escolha está aportado no fato de que a oferta de Educação Básica constitui-se em fenômeno recente no Distrito, haja vista que as áreas rurais de pequenos municípios brasileiros tiveram um processo de escolarização tardio e sexista. Aspectos como a distância da sede do Município, a densidade demográfica e as marcas de isolamento também motivaram a realização do estudo. $\mathrm{O}$ colégio no qual foram localizados os/as jovens é uma instituição de ensino fundamental de $1^{\mathrm{a}}$ a $8^{\mathrm{a}}$ série da rede pública do referido município que funciona nos turnos: matutino, vespertino e noturno.

$\mathrm{Na}$ tentativa de reconhecer as especificidades que caracterizam os contextos locais do meio rural, optouse por realizar uma pesquisa etnográfica, na qual a observação participante e os grupos de discussão se constituíram como principais instrumentos de coleta de dados. Os grupos de discussão foram formados com jovens estudantes do sexo masculino e feminino, a partir do critério da amizade, ou seja, os próprios jovens determinavam quem participaria do grupo, com a presença de três a seis integrantes por grupo. Foi realizado um total de dez grupos de discussão com jovens oriundos do Distrito e fazendas vizinhas, alunos da $5^{\mathrm{a}}$ a $8^{\mathrm{a}}$ série, faixa etária de 12 a 18 anos, entre os meses de fevereiro e março de 2008.

Em seguida, deu-se início à análise dos dados empíricos. Inicialmente, realizou-se a transcrição e divisão temática dos grupos de discussão realizados com os jovens. Essa divisão compreende a identificação das passagens/sub-passagens e da metáfora de foco. Embora todos trouxessem aspectos importantes para ser analisados, a escolha de grupos representativos para análise era necessária. Nesse sentido, foi feita a transcrição ${ }^{1}$ completa e codificada de três grupos, tendo o cuidado de preservar as marcas de oralidade dos entrevistados, na tentativa de garantir o reconhecimento do dialeto local e da densidade interativa presente nos grupos. Para a análise, foram escolhidos os grupos 'Os/as jovens que vêm de longe' e 'As meninas que sonham.' A escolha está aportada nas especificidades apresentadas pelos referidos grupos, tais como o local de moradia e as representações de gênero. $\mathrm{O}$ processo de análise destes, foi feito a partir 
do método documentário de interpretação desenvolvido por Karl Mannheim e adaptado para a pesquisa social empírica por Ralf Bohnsack (WELLER et al, 2002).

Considerando os limites do presente artigo, serão apresentados, a seguir, alguns segmentos do eixo Ser jovem no meio rural, dos grupos de discussão 'As meninas que sonham' e 'Os/As jovens que vêm de longe'. No primeiro momento, faz-se uma breve apresentação do perfil dos/das participantes dos grupos. Em seguida, a análise do referido eixo que se propõe a entender os sentidos atribuídos pelos/pelas jovens aos modos de socialização instituídos para moças e rapazes, no meio rural.

\section{Perfil do Grupo de Discussão: As meninas que Sonham}

\section{Daniela}

Daniela tem 14 anos, religião católica, branca, natural da fazenda Angico, em Palmas de Monte Alto. Mora em Espraiado, há 12 anos, com os pais. Tem 5 irmãos . Sua mãe nasceu na fazenda Angico, tem o ensino fundamental incompleto, é gari e ganha $\mathrm{R} \$ 70,00$ por mês. Seu pai nasceu em Angico, tem ensino fundamental incompleto, trabalha em associação. Não informou a renda do pai. Daniela estudou a $1^{\text {a }}$ etapa do ensino fundamental na Escola Municipal Wilson Lins, em Espraiado. Cursa a $8^{\mathrm{a}}$ série e trabalha ajudando em casa, durante a semana. Seu lazer preferido é jogar baleado. Não participa de grupo ou associação.

\section{Bruna}

Bruna tem 14 anos, religião católica, negra, natural de Guanambi. Mora na fazenda Muquém com os pais, desde que nasceu. Tem 4 irmãos. Sua mãe nasceu na fazenda Muquém, trabalha em casa e tem o ensino fundamental completo. Seu pai nasceu na fazenda Muquém, é agricultor e tem ensino fundamental completo. Não informou a renda dos pais. Bruna estudou a $1^{\mathrm{a}}$ etapa do ensino fundamental na Escola Municipal Wilson Lins, em Espraiado. No momento, atual, cursa a $8^{\mathrm{a}}$ série. Seu lazer preferido é o futebol. Não participa de grupo ou associação.

\section{Geane}

Geane tem 12 anos, religião católica, branca, natural de Palmas de Monte Alto. Mora com os pais em Vesperina, desde que nasceu. Tem 1 irmã. Sua mãe é professora, tem ensino superior completo e Pósgraduação lato sensu. Seu pai é funcionário da limpeza geral e tem o ensino fundamental completo. Não soube informar a naturalidade dos pais. Também não informou a renda de ambos. Estudou a $1^{\mathrm{a}}$ série do Ensino fundamental no Colégio Municipal Marciano Antonio Batista, localizado em Vesperina e a $2^{\mathrm{a}}, 3^{\mathrm{a}}$ e $4^{\mathrm{a}}$ séries na Escola Municipal Wilson Lins, em Espraiado. No momento, cursa a $8^{\mathrm{a}}$ série. Seu lazer preferido é brincar. Não participa de grupo ou associação.

\section{Elaborações sobre o Lugar de Moças e Rapazes - 0 que Dizem as J ovens}

A condição de jovem moça no meio rural pode ser vivenciada de distintas formas, considerando que as conformações socioespaciais são pautadas por princípios e valores que regem aquele espaço. $\mathrm{Na}$ tentativa de compreender as experiências partilhadas pelas jovens, a entrevistadora propõe uma questão sobre os significados de ser jovem moça e morar no meio rural (Passagem Ser Jovem, linhas 287-309):

Y: Como é que é ser garota né ser moça ser jovem e morar onde vocês moram?

Df: Pra mim é bom porque ser assim jovem isso tudo que ce falou garota moça é bom que (1) criança a gente não sabe de nada tudo que fala é da boca pra fora não sabe (1), gente sendo assim moça, gente vai compreendendo mais as coisa vai vendo como é que as coisa funciona que né assim como gente pensa assim que é tudo facim não ((criança conversando na janela)) como eu tava dizendo é bom porque às vezes às vezes gente assim pensa assim de criança ah é é fácil eu vou lá e faço e tá bom ninguém vai me bater ninguém vai me matar eu falo isso e, da boca pra fora todo mundo tá sabendo que criança não tem juízo e já vai ficando moça, como nós estamos aqui, nós vamos perceber, nós vamo repender daquilo que nós falamo nós falamo aquilo da boca pra fora, mas agora nós tamo vendo que as coisas não é assim facim que nem como nós pensava, agora nós tamo vendo outras crianças falando, nós reclamando e eles tão do mesmo jeito, nós não pode nem reclamar porque nós também fazia do mesmo jeito

Gf: Pra mim assim é ruim que eu não conheço nada da adolescência eu já tô chegando perto do ponto eu queria ficar 
sempre pra criança

Tds: $\odot 3 \odot$

Gf: 4 Queria ficar sempre criança, não tinha que preocupar com nada

Bf: Pra mim é bom, porque na adolescência e mudei muito quando eu era criança era mais rebelde e tal, aqui às vezes acontece coisas assim (1) eu faço (_ ),mas eu sei, eu tenho juízo, eu sei o que eu faço já e $e$ ogente adolescente, gente tem mais consciência das coisas $^{\circ} e ́$

$D f$ :

$B f: E$

[]Conhecimento

Ser jovem moça é apontado como uma experiência positiva, dada a possibilidade de sair de uma condição de dependência e desconhecimento para uma condição de autonomia. As jovens falam sobre a transição da infância para a adolescência como momento importante, pois passam a ser vistas como responsáveis. A condição de criança que 'não tem juízo', que 'tudo que fala é da boca pra fora', é substituída pela postura responsável de quem 'tem mais consciência das coisas'.

A referência positiva a essa transição não é compartilhada por Geane, que aponta a adolescência como momento ruim, desconhecido e novo, afirmação que provoca risos entre todas, talvez pela recusa explícita de Geane em aceitar a transição. Apesar de reconhecer a ocorrência das mudanças biológicas em seu corpo, formula de maneira entusiasmada a possibilidade de continuar 'sempre criança', pois essa condição não está relacionada às preocupações.

Embora as jovens ressaltem o aspecto positivo da juventude, destacam a assunção de responsabilidades como aspecto que perpassa a condição de ser jovem. Para elas, a experiência de ser jovem requer que tenham postura responsável frente às situações que lhes são colocadas, o que demonstra a existência de uma autoavaliação pautada em princípios rígidos de conduta. As jovens parecem conceber que esse momento se traduz em uma experiência marcada pela tensão, pois a 'espreita' constante as acompanha, como fica expressa na exemplificação de Daniela: 'já vai ficando moça (...), nós vamos percebendo, nós vamos repender daquilo que nós falamos'. Em outras palavras, os comportamentos assumidos são pensados a partir da sua condição como jovem ou criança. Um aspecto que fortalece essa tensão é a ambiguidade com que os adultos tratam os jovens. Existe uma imprecisão por parte daqueles que olham e percebem esses sujeitos. Assim, muitos jovens resistem às transições, haja vista as permanentes cobranças. Às vezes, é melhor permanecer criança, fugindo da maturidade e das obrigações.

As relações tecidas por rapazes e moças estão ancoradas em papéis sociais distintos durante o processo de socialização a que foram submetidos no meio rural. $\mathrm{O}$ entendimento das diferenças entre a vida das moças e a vida dos rapazes é necessário para saber como as relações entre estes são estabelecidas (Ser jovem moça e ser jovem rapaz, linhas 310-348):

Y: Vocês acham que tem diferença é (2) da vida das moças pra vida dos rapazes, vocês acham que é diferente?

Gf: Eu acho que ser rapaz é mais melhor (2), eu acho né, se bem que eu não sou um

Df: É, eu também, apesar de eu também nãao ser um rapaz eu desejaria ser, porque acho que é melhor, porque as as moças assim, (1) como diga mulher tudo=tudo que que faz ta na na boca do povo, faz uma coisa hoje, amanhã já tá na boca do povo, e rapaz não, tudo que rapaz faz nada cai nele, nada assenta nele (2), tudo só assenta nas costas das moças

Gf: Fala que as muié é isso que as muié é aquilo

Df: []É que que tava com com com não sei quem ontem, que hoje já tá com não sei quem (1) e ás vezes, às vezes assim, a maioria dos povo fala fala fala as coisa assim, que nem sabe, não vê só só só ouviu uma pessoa falar lá mentiu ouviu a pessoa mentiu, pronto já já começou a espalhar

Bf: E pra mim ser rapazé (.) melhor e ruim, porque tem os rapaz de hoje, não todos, mas alguns não não pensam mais em respeitar as moças não não tem responsabilidade e só quer (1) só quer bagunçar, não quer (1) ter respeito não quer ter assim (2) responsabilidade em (1) na-,opor exemplo, namorar uma moça em ficar com uma pessoa isso

$D f:$

$B f: E^{\prime}$

[]respeitar

Df: A maioria dos dos dos rapazes hoje não tá pensando mais assim em paz, ficar assim com uma pessoa, assim se direito e ficar com uma pessoa direita né, assim, um rapaz ser direito e ficar com uma moça, assim, que não respeita ele que hoje tá com ele, amanhã tá com outro e depois já tá com outro e vai (2), vai seguindo e a maioria dos rapaz hoje só pensa assim na violência, em matar, em roubar, em bater, em a maio,- 
nem todas, a maioria das moças só pensa nisso é (2) passa no jornal a maioria das moças assim adolescentes de 13 anos 10 anos, tá 10 anos uma criança é (1) dando luz a uma outra criança

Gf: Se prostituindo

Df: É prostitu- prostituindo

(3)

Bf: $E$ deveria ser mais diferente com as moças soubesse respeitar os rapaz os rapaz respeitar a moça e tudo viver em correta Df: Mas às vezes também

$B f:$

[]correta forma

$D f:$ Mas, às vezes, as moças respeita os rapaz enquanto a enquanto que tem moça, assim, que tá namorando o rapaz e não gosta, assim, de sair pra rua para não dar lugar os povo falar, enquanto a moça tá lá em casa pensando o que vai fazer, rapaz ta aqui, na rua com outra, colocando dois pares de chifre $(-) ;$

$B f: E^{\prime}$

Bf: Acho que só né $\odot 2$ ()

Df: Pra mim é só e você Geane?

As elaborações sobre a vida de moças e rapazes na comunidade giram em torno da positividade da condição de vida dos rapazes apontada pelas jovens. A atribuição desse significado à condição de ser rapaz é motivada pelo lugar ocupado por moças e rapazes na localidade, especialmente nos espaços públicos de socialização. As jovens são cerceadas pelo controle não só do núcleo familiar como também da comunidade que institui tratamento distinto para homens e mulheres, conforme a conveniência que rege a vida local.

O padrão de moralidade que pune as mulheres com a execração pública 'tudo que faz tá na boca do povo' é o mesmo que eleva os homens com a liberação de sua conduta, tal como expressa Daniela: "rapaz não, tudo que rapaz faz, nada cai nele, nada assenta nele". Estas diferenciações parecem indignar as jovens, que se mostram resistentes em aceitar as imposições de um modelo que as oprime. Esse padrão encontra ancoragem nas manifestações de controle e vigília, presentes nos espaços de circulação social. As interações estabelecidas entre moças e rapazes são observadas e julgadas conforme o sexo. Ocorre que, nem sempre, as observações realizadas em espaços frequentados pelas jovens primam pela veracidade dos fatos. Então, a fofoca que se 'espalha' na comunidade surge como mecanismo que reforça a exposição sofrida pelas moças: 'tudo só assenta nas costas das moças'.

Essa prática que se incumbe de depreciar, sobretudo aqueles historicamente discriminados como mulheres, bêbados, moradores de rua, mantém o funcionamento da vida comunitária. A ação de espalhar é garantida pelo falatório que se instala nas esquinas, portas de bares e comércios. É essa exposição 'maldita' que acompanha e coíbe os passos das jovens moças no Distrito, ainda que muitos 'fala as coisa assim que nem sabe'.

Embora avaliem positivamente a condição dos rapazes, as jovens também apontam os aspectos negativos presentes no comportamento destes. Afirmam que a maioria dos rapazes protagoniza cenas de violência, sobretudo contra a mulher, além de desrespeitar e bagunçar. Essa referência, pode estar relacionada a uma imagem negativa do distrito, ${ }^{2}$ no que se refere ao comportamento dos jovens rapazes. A exposição a situações de violência é apontada como uma escolha dos rapazes, que se recusam a ficar em paz. Essas manifestações, estão associadas à violência mais geral que atinge, sobretudo os jovens homens, em razão do esfacelamento social que segrega e os expõe a condições desiguais, especialmente no que se refere ao usufruto das benesses culturais. Destacam ainda, a importância de um relacionamento afetivo, em que o respeito e o cuidado com a relação seja papel do homem e da mulher, para que possam 'viver em correta forma'. No entanto, o modelo que inicialmente parece ser questionado, aparece na fala das jovens como ideal a ser mantido.

\section{Perfil do Grupo de Discussão: Os/As Jovens que Vêm de Longe}

\section{Moisés}

Moisés (Mm) tem 17 anos, religião católica, negro, natural da fazenda Cedro, em Palmas de Monte AltoBA. Mora nessa fazenda desde que nasceu na companhia dos pais. Tem 7 irmãos. Sua mãe nasceu na fazenda Malhada Grande, é lavradora e ganha R $\$ 15,00$ por dia. Seu pai nasceu na fazenda Papaconha, é lavrador e ganha $\mathrm{R} \$ 15,00$ por dia. Ambos cursam a Educação de Jovens e Adultos à noite, na fazenda Cedro. Moisés estudou a $1^{\mathrm{a}}$ etapa do ensino fundamental na Escola Municipal Santo Onofre, localizada na fazenda Cedro. No momento atual, cursa a $8^{a}$ série e seu lazer preferido é praticar esportes. Frequenta um grupo há há seis meses na igreja, de quinze em quinze dias, para brincar e realizar atividades orais. 


\section{Tatiana}

Tatiana (Tf) tem 13 anos, religião católica, negra, natural da fazenda Cedro, em Palmas de Monte Alto. Mora nessa fazenda desde que nasceu com os pais. Tem 7 irmãos. Sua mãe é zeladora e foi a primeira professora da localidade. Tatiana não informou a naturalidade dos pais, a renda, a escolaridade e a ocupação do pai. Estudou a $1^{\text {a }}$ etapa do ensino fundamental na Escola Municipal Santo Onofre, localizada na fazenda Cedro. Atualmente, cursa a $5^{\text {a }}$ série e tem como lazer preferido estudar. Frequenta um grupo, a cada quinze dias, há 6 meses, na igreja.

\section{Carla}

Carla (Cf) tem 16 anos, religião católica, negra, natural da fazenda Cedro, em Palmas de Monte Alto. Mora nessa fazenda desde que nasceu, com os pais. Tem 9 irmãos. Sua mãe nasceu em Malhada, trabalha em casa e cursa a Educação de jovens e adultos à noite na fazenda Cedro. Seu pai é lavrador e ganha $\mathrm{R} \$ 15,00$ por dia. Carla não informou a escolaridade dos pais e a naturalidade do pai. Estudou a $1^{\mathrm{a}}$ etapa do ensino fundamental na Escola Municipal Santo Onofre, localizada na fazenda Cedro. Atualmente, cursa a $6^{\text {a }}$ série e tem como lazer preferido brincar de futebol com as amigas. Participa de um grupo há três meses. Encontram-se a cada quinze dias, na igreja, para fazer leituras bíblicas e brincar.

\section{Wesley}

Wesley (Wm) tem 14 anos, religião católica, negro, natural da fazenda Cedro, em Palmas de Monte Alto. Mora nessa fazenda desde que nasceu, com os pais. Tem 4 irmãos . Sua mãe é lavradora e ganha $R \$ 15,00$ por dia. Seu pai é lavrador e ganha $\mathrm{R} \$ 15,00$ por dia. Ambos, estão cursando a Educação de Jovens e Adultos à noite, na fazenda Cedro. Wesley não informou a escolaridade e a naturalidade dos pais. Estudou a $1^{\text {a }}$ etapa do ensino fundamental na Escola Municipal Santo Onofre, localizada na fazenda Cedro. Atualmente, cursa a $7^{\mathrm{a}}$ série e tem como lazer preferido jogar futebol. Participa de um grupo, há seis meses, a cada quinze dias, na igreja de Santo Expedito. Nesse grupo, realiza atividades orais e brincadeiras.

\section{Carlos}

Carlos $(\mathrm{Cm})$ tem 16 anos, religião católica, negro, natural da fazenda Cedro, em Palmas de Monte Alto. Mora nessa fazenda desde que nasceu, com os pais.
Tem 7 irmãos (informa ainda que morreram 8 irmãos). Sua mãe nasceu em São Paulo, é zeladora e tem o ensino fundamental completo. Seu pai é lavrador. Não informou a renda dos pais, bem como, a escolaridade e naturalidade do pai (escreveu que não sabe a naturalidade do pai). Estudou a $1^{\mathrm{a}}$ etapa do ensino fundamental na Escola Municipal Santo Onofre, localizada na fazenda Cedro. Cursa a $6^{\mathrm{a}}$ série e trabalha na 'panha' de feijão. Informa que trabalha $3 \mathrm{~h}$ e que o valor que ganha gasta com alimentação. Seu lazer preferido é o jogo de futebol. Participa de um grupo há 1 ano, 2 vezes, para rezar, brincar e cantar rezas.

\section{João}

João (Jm) tem 18 anos, religião católica, negro, natural de Palmas de Monte Alto. Mora na fazenda Curral Novo desde que nasceu, com os pais. Tem 6 irmãos (morreram 2 irmãos). Sua mãe nasceu em Candiba, é lavradora e ganha $\mathrm{R} \$ 15,00$ por dia. Seu pai é lavrador e ganha $\mathrm{R} \$ 15,00$ por dia. Informa não saber a escolaridade dos pais e a naturalidade do pai. Estudou a $1^{\text {a }}$ etapa do ensino fundamental na Escola Municipal José Pinto Lima, localizada na fazenda Curral Novo. Cursa a $7^{\mathrm{a}}$ série e trabalha. Seu lazer preferido é jogar futebol. Participa de um grupo há 1 ano, a cada quinze dias. Nesse grupo, reza, brinca e realiza atividades orais.

\section{Rapazes e Moças Convivem Bem}

As experiências partilhadas pelo grupo 'Os/as jovens que vêm de longe' fortalecem os laços de convivência, ao mesmo tempo em que garantem a existência de um 'modo' de ser jovem, sustentado num ethos comunitário específico. Os significados atribuídos por esses jovens à sua condição de vida, na comunidade, devem ser entendidos a partir da influência da dimensão socioespacial na constituição de um determinado modo de ser jovem (Dayrell, 2005). A questão proposta sobre as possíveis diferenças existentes entre ser uma jovem moça e ser um jovem rapaz busca compreender como vivenciam essa condição na fazenda Cedro (Passagem Ser jovem, linhas 126-139):

Y: Como é que é ser rapaz né ou ser moça lá na região? Tem alguma diferença entre rapaz e moça lá?

Wm: Pode até ser que tem alguma vez que tem alguma diferencinha assim, mas os rapaz e as moças lá se estão namorando 
convive bem

Cm: A diferença lá, né, é só assim no relacionamento, agora na amizade, assim, não tem diferença não

Wm: Nos dias mesmos de encontro de jovens, que a gente faz lá, na igreja reúne todos os rapaz e as moça lá, na igreja lá e (2) tudo certo lá, nosso relacionamento

Jm: Pra mim também não

Mm: $O$ jeito dos rapaz e as moças lá na reg- na fazenda Cedro tá indo bem (2), todos procurando procurar a comunidade dia de domingo à noite, no encontro de jovens as moças celebra o culto e os rapaz. ( ) já é adolescente preocupa mais com o futebol, essas coisa assim (1) mas isto Cf: Em vez do que a gente vê, falar assim da cidade de fora, lá onde a gente mora tá tá tá bem por porque os os rapaz respeita as as menina e tudo assim (1) aí (2) (-) 3 .)

Tf: $: 2 \odot$ eu também acho

A igreja é local para 'cantar rezas' e orar, mas também para brincar. Constitui-se em espaço lúdico e de lazer, dada a possibilidade que oferece para que se divirtam entre os pares. Figura como espaço de encontro dos/as jovens da fazenda Cedro, que partilham experiências e constroem vínculos que vão além das tarefas do culto dominical.

Esse momento de partilha, organizado por eles próprios, reunião de moças e rapazes na igreja aos domingos, aponta a dimensão socializadora dos templos religiosos existentes no meio rural. Nessas localidades, a vida social passa pela existência da igreja e da escola, que se constituem em espaços destinados, sobretudo, à prática da leitura e da escrita. A apropriação dos códigos da língua na escola possibilita exercer com êxito as atividades demandadas pela igreja. Daí que, para muitos moradores, essas instituições são necessárias para garantir a sua condição de sujeito atuante na comunidade.

Como participantes do grupo de jovens, os rapazes e as moças da fazenda Cedro apresentam-se perante a comunidade local numa condição diferenciada. Embora os rapazes frequentem o culto, cabe às moças celebrá-lo. Ao complementar a fala de Wesley sobre os encontros religiosos, Moisés parece afirmar que a construção dos papéis assumidos pela jovem moça e pelo jovem rapaz passa também pela existência da igreja. Tal como fica expresso em sua fala: 'as moça celebra o culto e os rapaz ( ), já adolescente preocupa mais com o futebol', as práticas de sociabilidades estão ancoradas em padrões de comportamento que definem o lugar social do sujeito no meio em que vivem. Como o futebol sempre foi um espaço masculino, é provável que a organização dos templos religiosos seja atribuição das mulheres, tal como o é a casa, mundo feminino.

Esse modelo de relação construído ainda na infância, nos permite pensar o cotidiano de meninos e meninas no meio rural. Nos anos iniciais, observa-se que não há muitas diferenças na socialização de ambos no que se refere à vivência do lúdico. No entanto, à medida que crescem, o lazer dos meninos se amplia consideravelmente, representado pelo jogo de bola e os banhos de rio, enquanto as meninas são iniciadas nos ritos do trabalho doméstico e na celebração dos cultos na igreja.

Mas para os/as jovens do Cedro, são as manifestações de respeito e amizade nos tempos de lazer que sustentam a boa convivência no local. A alegria de estar na companhia de amigos e amigas tanto em encontros religiosos como no jogo de futebol, nas feiras, nos casamentos e banhos de rio assegura o momento das risadas, da resenha ${ }^{3}$ entre os pares, a partilha da confiança, o que só reforça a amizade e garante a dimensão educativa desses encontros. Relações pautadas, nesses princípios, parecem impedir que esses jovens concebam a cidade como espaço mais atraente, tal como assinala a fala de Carla e em concordância a de Tatiana: 'Em vez do que a gente vê falar assim da cidade de fora, lá onde a gente mora tá bem porque os rapaz respeita as menina'. É possível que esses/as jovens, ao valorizarem suas amizades locais, a partir da negação do modelo de convivência nas cidades, estejam buscando também se afirmar positivamente como jovens rurais.

A crise das cidades representada pela existência de problemas sociais como violência, desemprego, miséria, drogas, entre outros, possibilita apontar a localidade de origem como lugar que 'tá indo bem', como lugar que é bom e onde é possível viver a sua condição de jovem. O convívio familiar e os laços de amizade tornam a vida no campo significativa e desejada, haja vista a mobilização de muitos jovens para permanecer no local onde 'nasceu e foi criado'.

A comparação entre a vida no campo e na cidade realizada por Carla permite ainda rever a ideia historicamente difundida do campo como lugar miserável, onde vivem pessoas ignorantes, atrasadas e individualistas. Se a distância das cidades pode dificultar o usufruto de bens culturais e de serviços, a vida na localidade possibilita uma vivência juvenil aportada nas dimensões de respeito, amizade e partilha. O acesso aos meios de comunicação de massa possibilita saber como é que se vive na cidade, ao mesmo tempo em que liberta o campo da imagem depreciativa de lugar ruim para viver. Para os/as 
jovens, essa revisão passa a ser possível a partir do acesso às informações difundidas sobre o mundo e as cidades. A disseminação desses canais nas áreas rurais possivelmente influencia nas percepções sobre os universos do campo e da cidade, pois as relações entre estes foram reconfiguradas, o que impossibilita pensar o rural sem considerar a influência das cidades.

\section{Algumas Considerações sobre os Grupos de Discussão}

Os resultados da pesquisa desenvolvida, apontam a tensão experienciada pelo grupo: 'As meninas que sonham', que se mostra resistente ao modelo de comportamento instituído para moças e rapazes no meio rural. As jovens mostram-se indignadas com a forma como são vistas e tratadas na comunidade, especialmente porque tudo 'só assenta nas costas das moças,' enquanto que para os rapazes 'nada cai nele [s], nada assenta nele [s]'. Essa observação, se traduz em denúncia de uma socialização de rapazes e moças distinta e eficiente, que está aportada num padrão de conduta rígido e moralista para com o sexo feminino.

Para os rapazes e as moças do grupo: 'Os/as jovens que vêm de longe', é relevante viver num lugar onde o respeito perpassa as relações tecidas tanto nos espaços de lazer como nos espaços de trabalho, o que torna a existência significativa. Os/as jovens reiteram esse valor destacando o comportamento respeitoso dos rapazes para com as moças - 'os rapaz respeita as menina' -, que segundo Carla não ocorre nas cidades. Assim, ao contrário de muitos jovens rurais que transitam no meio urbano para estudar, trabalhar e se divertir, 'os/as jovens que vêm de longe' vivem a sua condição de moça e rapaz apenas no meio rural e de forma intensa, haja vista a existência de diversos espaços destinados às práticas de sociabilidade. Esse modo de ser jovem possibilita rever concepções que apontam o rural como lugar sem lazer, destituído de lugares para diversão.

As orientações coletivas desses dois grupos no tocante às relações estabelecidas entre moças e rapazes, na comunidade, são bem distintas. Os/as jovens que vivem na fazenda Cedro parecem vivenciar o cotidiano de forma menos conflitante, sobretudo nas trocas experimentadas nos espaços de lazer. Os membros dos dois grupos moram em áreas distintas, fazenda Cedro e sede do Distrito Espraiado, sendo que esses espaços apresentam singularidades, especialmente no que se refere à organização sóciocultural da localidade. É possível que a referência à sede do Distrito como lugar de jovens violentos, onde 'a lei demora a chegar,' seja um elemento que favoreça elaborações tão distintas por parte dos dois grupos.

Tal abordagem sugere o desenvolvimento de estudos que se destinem a investigar o processo de socialização de moças e rapazes em distintos contextos do meio rural brasileiro, considerando as dimensões de trabalho, educação, pertencimento étnico e classe.

1 Os códigos utilizados na transcrição das entrevistas foram desenvolvidos pelos pesquisadores do grupo coordenado por Ralf Bonhsack, na Alemanha (cf. Anexo I). Weller (2005) considera relevante numerar as frases dos membros do grupo, bem como criar códigos para apresentar a entonação da voz e as expressões produzidas pelos participantes. Também assinala a importância de apresentar nomes fictícios para os membros, garantindo assim o anonimato destes.

2 As ocorrências de cenas de violência envolvendo jovens, há tempos atrás, favoreceu a construção da imagem do distrito no Município como lugar violento.

3 Resenha - brincadeiras feitas entre os colegas

\section{Referências}

ABRAMO, Helena Wendel; BRANCO, Pedro Paulo Martoni. (Org.). Retrato da juventude brasileira: análise de uma pesquisa nacional. São Paulo: Editora Fundação Perseu Abramo, 2005.

ABRAMOVAY, Ricardo. (Org.). Juventude e agricultura familiar: desafios dos novos padrões sucessórios. Brasília: Unesco, 1998.

BRANDÃO, Carlos Rodrigues. A partilha da vida. São Paulo: GEIC/Cabral, 1995.

CASTRO, Elisa Guaraná de; CARNEIRO, Maria José (Org.). Juventude rural em perspectiva. Rio de Janeiro: Mauad X, 2007.

DAYRELL, Juarez Tarcísio. A música entra em cena: o rap e o funk na socialização da juventude. Belo Horizonte: UFMG, 2005.

“A escola "faz" as juventudes ?" Educação e Sociedade, v.28, n. 100, p.1105-1128, out. 2007. 
MARGULIS, Mario y URRESTI, Marcelo. "La juventud es más que una palabra". In: ___ (editor). La juventud es más que una palabra: ensayos sobre cultura y juventud. Buenos Ayres: Biblos, 1996, p. 13-30.

PAIS, José Machado. Vida cotidiana - enigmas e revelações. São Paulo: Cortez, 2003 b.

Culturas juvenis. $2^{\mathrm{a}}$ ed. Lisboa: Imprensa Nacional - Casa da Moeda, 2003a.

PEREIRA, Jorge Luiz Goes. "Entre campo e cidade: amizade e ruralidade segundo jovens de Nova Friburgo". Estudos, Sociedade e Agricultura, v.12, n.1, p.322-351, 2004.

SILVA, Vanda. Sertão de jovens. São Paulo: Cortez, 2004.

STROPASOLAS, Valmir Luís. O mundo rural no horizonte dos jovens. Florianópolis: Editora da UFSC, 2006.

VEIGA, José Eli da. Cidades imaginárias - o Brasil é menos urbano do que se calcula. $2^{\mathrm{a}}$ ed. Campinas, SP: Autores Associados, 2003.

VIEIRA, Rosângela Steffen."Tem jovem no campo! Tem jovem homem, tem jovem mulher". In: WOORTMANN, Ellen F.; MENACHE, Renata; HEREDIA, Beatriz (Org.). Margarida Alves coletânea sobre estudos rurais e gênero. Brasília: MDA, IICA, 2006, p. 195-214.

WANDERLEY, Maria de Nazareth Baudel. (coord). Juventude rural: vida no campo e projetos para o futuro. Recife, 2006. Relatório de Pesquisa.

WELLER, Wivian. "A contribuição de Karl Mannheim para a pesquisa qualitativa: aspectos teóricos e metodológicos". Sociologias, n.13, p. 260300, jan./abr. 2005.

et al. "Karl Mannheim e o método documentário de interpretação: Uma forma de análise das visões de mundo". Sociedade e Estado (Dossiê Temático: Inovações no campo da metodologia das ciências sociais), v.17, n. 2, p.375-396, jul./dez. 2002.

. "Grupos de discussão na pesquisa com adolescentes e jovens: aportes teórico-metodológicos e análise de uma experiência com o método". Educação e Pesquisa. Revista de Educação da USP, v.32, n. 2, p.241-260, mai./ago. 2006.

\section{Anexo l: Códigos Utilizados na Transcrição das Entrevistas (modelo criado pelos pesquisadores do grupo coordenado por Ralf Bohnsack)}

Y: abreviação para entrevistador (quando realizada por mais de um entrevistador, utiliza-se Y1 e Y2)

Am/Bm: abreviação para entrevistado/entrevistada. Utiliza-se "m" para entrevistados do sexo masculino e "f" para pessoas do sexo feminino. Numa discussão de grupo com duas mulheres e dois homens, por exemplo, utiliza-se: Af, $\mathrm{Bf}, \mathrm{Cm}, \mathrm{Dm}$ e dá-se um nome fictício ao grupo. Essa codificação será mantida em todos os levantamentos subsequentes com as mesmas pessoas. Na realização de uma entrevista narrativa-biográfica com um integrante do grupo entrevistado anteriormente, costuma-se utilizar um nome fictício que inicie com a letra que a pessoa recebeu na codificação anterior (por exemplo: Cm, Carlos).

?m ou ?f: utiliza-se quando não houve possibilidade de identificar a pessoa que falou (acontece algumas vezes em discussões de grupo quando mais pessoas falam ao mesmo tempo).

(.) um ponto entre parênteses expressa uma pausa inferior a um segundo.

(2) o número entre parênteses expressa o tempo de duração de uma pausa (em segundos).

$\Gamma \quad$ utilizado para marcar falas iniciadas antes da conclusão da fala de outra pessoa ou que seguiram após uma colocação.

; $\quad$ ponto e vírgula: leve diminuição do tom da voz.

ponto: forte diminuição do tom da voz.

vírgula: leve aumento do tom da voz.

exempalavra foi pronunciada pela metade.

exem:::plo pronúncia da palavra foi esticada ( a quantidade de : equivale o tempo da pronúncia de determinada letra).

assim=assim palavras pronunciadas de forma 
Socialização e Modos de Ser Jovem em Área Rural na Bahia

emendada.

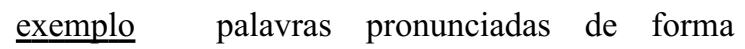
enfática são sublinhadas.

${ }^{\circ}$ exemplo ${ }^{\circ}$ palavras ou frases pronunciadas em voz baixa são colocadas entre pequenos círculos.

exemplo palavras ou frases pronunciadas em voz alta são colocadas em negrito.

(example) palavras que não foram compreendidas totalmente são colocadas entre parênteses.

( ) parênteses vazios expressam a omissão de uma palavra ou frase que não foi compreendida (o tamanho do espaço vazio entre parênteses varia de acordo com o tamanho da palavra ou frase).

(-) exemplo (-) palavras ou frases entre risos são colocadas entre emoticon.

(-) (2) () número entre sinais de emoticon expressa a duração de risos assim como a interrupção da fala.

((bocejo)) expressões não-verbais ou comentários sobre acontecimentos externos, por exemplo: ((pessoa acende cigarro)), ((pessoa entra na sala e a entrevista é brevemente interrompida)) ((risos)).

//hm// utilizado apenas na transcrição de entrevistas narrativas-biográficas para ou // (; (1) (-)// indicar sinais de feedback ("ah," “oh," “mhm”) ou risos do entrevistador. 